\title{
A drilling case study in polymer composites reinforced by virgin and recycled carbon fibres (CFRP and rCFRP) to analyse thrust force and torque
}

\author{
Norbert Geier ${ }^{1}\left[\right.$. Dániel István Poór ${ }^{1}$. Csongor Pereszlai ${ }^{1}$. Péter Tamás-Bényei ${ }^{2,3}$ • Jinyang Xu ${ }^{4}$
}

Received: 6 December 2021 / Accepted: 17 February 2022 / Published online: 24 February 2022

(c) The Author(s) 2022

\begin{abstract}
A great deal of attention is currently paid to recycling or reusing carbon fibres, as it improves sustainability and the lifetime of carbon products. The applicability of recycled carbon fibre-reinforced polymer (rCFRP) composite materials is supported by the results of material scientists; however, the machinability of rCFRPs has not been analysed yet. The machinability of virgin and rCFRPs was compared by analysing cutting force and torque in drilling. Six different CFRPs (virgin and recycled CFRPs with different reinforcing structures) were drilled at three feed levels using two different solid carbide cutting tools. The cutting force and torque were measured with a KISTLER 9257BA dynamometer, processed, and analysed by fast Fourier transformation (FFT) and analysis of variance (ANOVA). The experimental results proved at a significance level of 0.05 that the recycled/virgin status of the applied CFRPs significantly influences both the thrust force and drilling torque of each CFRP. Furthermore, the cutting force and torque are higher in rCFRPs than in virgin CFRPs at each reinforcing structure. The present study suggests spreading rCFRP applications, as there are no essential barriers against them from the point of view of drilling force and torque.
\end{abstract}

Keywords Recycled CFRP $\cdot$ Drilling $\cdot$ Cutting force $\cdot$ Torque

\section{Introduction}

Carbon fibre-reinforced polymer (CFRP) composites have superior material properties, like excellent specific strength, good chemical and dimensional stability, high damping ability, outstanding corrosion resistance, and good damage tolerance [1]. Therefore, the use of CFRP is spreading fast in

Norbert Geier

geier.norbert@gpk.bme.hu

1 Department of Manufacturing Science and Engineering, Faculty of Mechanical Engineering, Budapest University of Technology and Economics, Múegyetem rkp. 3, Budapest 1111, Hungary

2 Department of Polymer Engineering, Faculty of Mechanical Engineering, Budapest University of Technology and Economics, Múegyetem rkp. 3, Budapest 1111, Hungary

3 MTA-BME Research Group for Composite Science and Technology, Múegyetem rkp. 3, Budapest 1111, Hungary

4 State Key Laboratory of Mechanical System and Vibration, School of Mechanical Engineering, Shanghai Jiao Tong University, Shanghai 200240, People's Republic of China the high tech sectors (e.g., the aerospace, marine, defence, and energy industries [2]), and there is a need to extend the lifetime of CFRP components to increase their efficiency and sustainability $[3,4]$. Recycling carbon fibres from CFRP composites through pyrolysis is a promising method to reduce carbon waste and ecological footprint, and pyrolysis is already available on an industrial scale [5, 6]. Although the early results of material scientists on the material properties of recycled CFRPs are promising, the applicability of the recycled CFRPs is not supported by any machinability experience.

Pimenta and Pinho [7] analysed the microchemical properties and reinforcement architectures of recycled carbon fibres. They achieved $80 \%$ of fibre strength and similar quality recycled fibres compared to virgin CFRPs. They highlighted that rCFRPs would spread in applications requiring high toughness or damage tolerance. van de Werken et al. [8] analysed randomly oriented $2 \mathrm{D}$ recycled carbon fibre mats and proved that the degree of alignment was the most significant factor influencing the strength and modulus of CFRP composites. Genna et al. [9] characterised CFRPs obtained from recycled carbon fibres through a resin infusion process. 
Based on their promising results concerning tensile, flexural, and impact strength, they expect a wide range of potential applications of rCFRPs in the near future.

Although the applications of recycled carbon fibre-reinforced polymer (rCFRP) composites are limited and no studies have been published on their machinability, their main cutting characteristics and challenges may be similar to those of virgin CFRPs: (i) difficult to cut mainly due to the inhomogeneous and anisotropic characteristics, and the abrasive wear effect of carbon fibres on the cutting tool $[10,11]$; (ii) chip removal mechanisms are mainly influenced by the fibre cutting angle $(\theta)$, followed by the cutting edge radius $\left(r_{\beta}\right)$ and rake angle $(\gamma)$ $[12,13]$; (iii) high axial cutting forces and inappropriate support of laminated CFRP layers result in significant machining-induced damage formations i.e. delamination, burrs, tearing, and fibre pull-outs [14-19]; (iv) difficult to clamp due to their relatively low stiffness and hardness [20]; and (v) often machined in dry condition because of the wettability of composites; furthermore, the removal of carbon chips from the cutting space often requires a vacuum equipment due to their adverse impact on machine tool elements and on human health [21].

Davim and Reis [22] experimentally analysed the influences of feed and cutting speed on power, specific cutting pressure and delamination in the drilling of virgin CFRPs. They proved that the feed has the most significant influence on the cutting energetics of CFRP composites. In addition, they observed that the workability of a conventional twist drill and a brad and spur drill differs significantly in terms of cutting force and delamination, as proved by other researchers [23, 24]. Although the cutting speed is often considered a key factor in metal cutting, its influence is not as significant in drilling virgin CFRPs [16, 22].

The knowledge of cutting force and torque is essential in the case of machining virgin CFRPs, in order to predict (or set) tool life and hole quality $[11,17]$. Even though there is a huge need for the mechanistic modelling of cutting force of CFRPs to understand the mechanics of cutting and predict cutting force, the recent models still need many fitting variables that make them challenging to implement $[11,25]$. Lee et al. [26] developed a robotic drilling technology by implicit force and position control to improve hole quality in virgin CFRPs. They could reduce entry delamination by $66.76 \%$. Xu et al. [27] highlighted that tool material and geometry are the two crucial factors affecting the tool performance in the drilling of CFRPs. Mainly due to the abrasive wear effect of carbon fibres on the cutting tool, a diamond coated solid carbide tool material is often recommended for efficient machining.

According to the recent experiences in the machining of virgin CFRPs, a relatively low cutting speed and a solid carbide tool material were selected as fixed parameters, and the feed and the cutting tool geometry was selected as independent variables (factors) in this study to reveal the key differences in drilling virgin and recycled CFRPs. Since little is known about the machinability of rCFRPs, the main aim of the present research study is to compare the machinability of recycled CFRPs and virgin CFRPs in terms of thrust force and drilling torque. Six different CFRPs (virgin and recycled CFRPs with different reinforcing structures) were drilled at three feed levels using two different solid carbide cutting tools. A secondary, but no less critical objective of the present study is to provide information and technological suggestions to support the spread of recycled CFRP applications.

\section{Experimental setups}

\subsection{Material properties}

The machinability, the mechanical and material structures of 6 different carbon fibre-reinforced (CFRP) composites were investigated. During the research project, recycled $(\mathrm{R})$ and virgin $(\mathrm{V})$ carbon reinforcing fibres were used in 3 different types of reinforcement structures: chopped tows (A - also called chopped pellet), nonwoven mats (B - also called felts) and milled fibres (C). They were supplied by an international carbon reinforcement manufacturer. The manufacturing parameters, times, and the target fibre content were chosen based on industrial recommendations and previous research experiences. Each CFRP plate was made from IPOX MH3010 epoxy resin and IPOX MH3124 cycloaliphatic amine-based hardener (the mixing ratio was 100:33). The chopped tow and nonwoven mat types of reinforcements were manufactured via compression moulding. They were hardened at $80{ }^{\circ} \mathrm{C}$ temperature and 100 bar pressure for $20 \mathrm{~min}$ ) with a Metal Fluid Engineering $30 \mathrm{~T}$ hydraulic press. The milled carbon fibre reinforcing structure was manufactured via silicone form casting (hardening at room temperature for $14 \mathrm{~h}$, post-cured at $60^{\circ} \mathrm{C}$ for $2 \mathrm{~h}$ under pressure in a Despatch LBB2-27-1CE drying oven). Plate thickness was set to $4 \mathrm{~mm}$ in each CFRP. The target fibre content of the composite plates was $20 \mathrm{wt} \%$. The exact coding of the experimental materials and important information about them can be found in Table 1. In Fig. 1, the taken pictures of applied reinforcing structures can be seen.

The mechanical properties of CFRPs that were relevant from the point of view of cutting force and torque were characterised. These properties were interlaminar shear strength, Charpy impact strength, flexural strength, and modulus. The interlaminar shear tests were carried out according to the MSZ EN ISO 14130:1998 standard in a Zwick Z005 universal tensile tester on five specimens of each material. The crosshead speed was set to $1 \mathrm{~mm} / \mathrm{min}$ during the tests, and the support length was $10 \mathrm{~mm}$. The samples until a complete break or $2 \mathrm{~mm}$ of maximum deflection were investigated. 
Table 1 Applied CFRP

composite materials

\begin{tabular}{lllll}
\hline Code & Recycled/Virgin & Reinforcing type & $\begin{array}{l}\text { Average reinforcement } \\
\text { length }(\boldsymbol{\mu m})\end{array}$ & Manufacturing \\
\hline VA & Virgin & Chopped & $5873 \pm 606$ & Compression moulding \\
VB & Virgin & Nonwoven mat & Quasi-infinite & Compression moulding \\
VC & Virgin & Milled & $45 \pm 28$ & Silicone form casting \\
RA & Recycled & Chopped & $6114 \pm 1439$ & Compression moulding \\
RB & Recycled & Nonwoven mat & Quasi-infinite & Compression moulding \\
RC & Recycled & Milled & $77 \pm 51$ & Silicone form casting \\
\hline
\end{tabular}

Charpy impact tests were performed according to the MSZ EN ISO 179-1:2010 standard using a Ceast Resil Impactor Junior with a $2 \mathrm{~J}$ hammer on five notched specimens of each material. The support length was $62 \mathrm{~mm}$, and the starting angle was $150^{\circ}$. Three-point bending tests were performed on a Zwick Z005 universal tensile tester. The crosshead speed was $10 \mathrm{~mm} / \mathrm{min}$ during the tests, and the support length was $64 \mathrm{~mm}$. We investigated the samples until a complete break. Every test was executed at room temperature and $45 \%$ relative humidity. The results of the tests are summarised in Table 2.

Based on the results of the material tests, the cutting force and torque are expected to be influenced significantly by the structure of reinforcement (A, B, C) and the recycled/virgin status of the reinforcement $(\mathrm{V}, \mathrm{R})$.

\subsection{Machining environment}

The machining experiments, as conventional drilling experiments, were carried out on a three-axis CNC milling machine (Kondia B640). A customised drilling fixture was developed, which was applied to position and fix the CFRP composite plates, and support them to minimise buckling, thus minimising the risk of delamination and burr formation. Two Ø10 $\mathrm{mm}$ uncoated solid carbide drilling tools with special composite machining geometries were used during the experiments: a brad and spur drill (THOMAS TDM 2L 23C110100) and a fishtail twist drill (THOMAS TDM 2L 23C100100), denoted as $\mathrm{T} 1$ and $\mathrm{T} 2$, respectively (Fig. 2). Due to the negative impacts of carbon chips on the elements of the CNC machine tool and human health [1], an industrial vacuum cleaner (Nilfisk GB733) was used during the drilling processes; for this reason, the experiments were carried out in dry conditions. During the drilling, the cutting force components were collected with a setup of a multicomponent dynamometer (KISTLER 9257BA), a multi-channel charge amplifier (KISTLER 5070), and a dynamic signal acquisition module (National Instruments USB-4431). The sampling frequency was $4000 \mathrm{~Hz}$ to record cutting force data at every 5 degrees of tool position. The force data were processed by a program written in the LabVIEW software, and the axial torque was calculated simultaneously. The tool a)

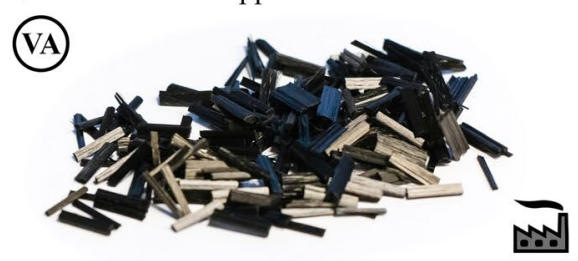

Avg. reinforcement length: $5873 \pm 606 \mu \mathrm{m}$

d)

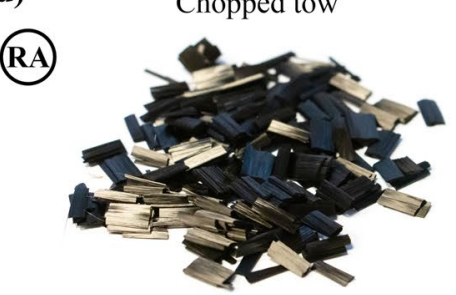

Avg. reinforcement length: $6114 \pm 1439 \mu \mathrm{m}$ b)

(VB

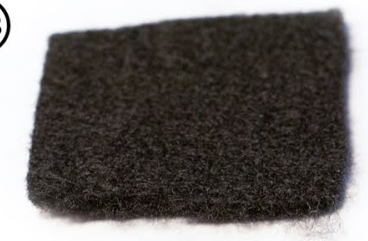

Avg. reinforcement length: quasi-infinite

e)

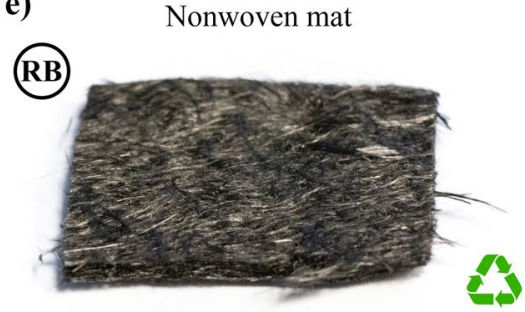

Avg. reinforcement length: quasi-infinite c)

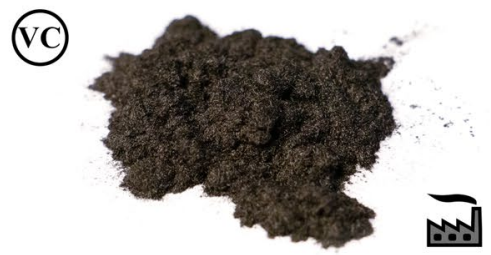

Avg. reinforcement length: $45 \pm 28 \mu \mathrm{m}$

f)

RC

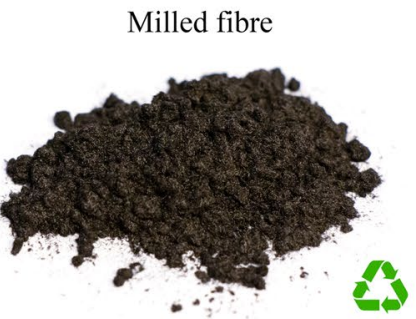

Avg. reinforcement length: $77 \pm 51 \mu \mathrm{m}$

Fig. 1 The six different fibre reinforcement types used in this study: a virgin chopped fibres, $\mathbf{b}$ virgin nonwoven mat, $\mathbf{c}$ virgin milled fibres, $\mathbf{d}$ recycled chopped fibres, e recycled nonwoven mat, and $\mathbf{f}$ recycled milled carbon fibres 
Table 2 The main mechanical properties of the investigated CFRP composites

\begin{tabular}{lclcc}
\hline Code & $\begin{array}{l}\text { Interlaminar shear } \\
\text { strength }(\mathbf{M P a})\end{array}$ & $\begin{array}{l}\text { Charpy impact } \\
\text { strength }\left(\mathbf{k J} / \mathbf{m}^{\mathbf{2}}\right)\end{array}$ & Flexural strength $(\mathbf{M P a})$ & $\begin{array}{l}\text { Flexural } \\
\text { modulus } \\
(\mathbf{G P a})\end{array}$ \\
\hline VA & $5.68 \pm 1.58$ & $7.05 \pm 3.42$ & $34.07 \pm 7.59$ & $2.85 \pm 0.29$ \\
VB & $12.07 \pm 1.08$ & $0.86 \pm 0.17$ & $74.17 \pm 2.53$ & $2.60 \pm 0.05$ \\
VC & $16.46 \pm 0.95$ & $1.23 \pm 0.29$ & $85.69 \pm 0.89$ & $5.06 \pm 0.21$ \\
RA & $6.99 \pm 1.44$ & $3.06 \pm 0.93$ & $32.21 \pm 5.09$ & $2.98 \pm 0.68$ \\
RB & $31.81 \pm 2.73$ & $2.63 \pm 0.03$ & $153.73 \pm 11.04$ & $6.75 \pm 0.36$ \\
RC & $19.79 \pm 1.38$ & $1.22 \pm 0.39$ & $104.78 \pm 5.46$ & $4.90 \pm 0.07$ \\
\hline
\end{tabular}

wear status significantly influences the energy needed for cutting [28]; therefore, the condition of the tool was monitored through digital images taken after each drilled hole with a Dino-Lite AM413ZT digital microscope (1.3 MPixel, $10 \times-60 \times$ and $200 \times$ magnification). The experimental setup can be seen in Fig. 2.

\subsection{Design of experiments}

The information gained earlier shows that feed, material type, and tool geometry may all substantially affect cutting force and torque [29]. The drilling experiments were carried out based on a randomised full factorial experimental design. The factors and their levels are listed in Table 3. The order of experimental setups was randomised in the case of each material. Each experimental run $(2 \cdot 3 \bullet 6=36$ runs $)$ was repeated five times (the total number of experiments was 180) in order to calculate reproducibility errors for the analysis of variance (ANOVA) approach.

The machining parameters were chosen by the recommendations of the tool manufacturer and the experiences of the authors: the cutting speed was set to $v_{c}=100 \mathrm{~m} /$ min $(3,183 \mathrm{rpm})$, and the feed was varied at three levels $\left(f_{1}=0.15, f_{2}=0.25, f_{3}=0.35 \mathrm{~mm} / \mathrm{rev}\right)$. Thrust force $\left(F_{t}\right)$ and drilling torque $\left(M_{z}\right)$ were chosen as output parameters with representative information about the energetics of cutting CFRPs. Both output parameters were calculated based on the data provided by the dynamometer, as follows: (i) first, the non-cutting related measured data were removed, then (ii) data were fast Fourier transformed (FFT) and (iii) a Butterworth filter removed the high-frequency vibrations at a cut off frequency of $f_{c}=550 \mathrm{~Hz}$, then (iv) the filtered FFT spectrum was inverse Fourier transformed, and finally, (v) the maximum values of the force and torque data were selected as $F_{z}$ and $M_{z}$, respectively. The response value-generation workflow is illustrated in Fig. 3.

\section{Results and discussions}

The calculated thrust force $\left(F_{t}\right)$ and drilling torque $\left(M_{z}\right)$ are presented and discussed in this chapter. The cutting ability of the machining tool is significantly influenced by its wear
Fig. 2 Machining experiment setup: a digital microscope to monitor tool condition, b special drilling fixture to support CFRP against buckling, c CFRP composite plate, $\mathbf{d}$ KISTLER dynamometer, e multi-channel charge amplifier, and $\mathbf{f}$ dynamic signal acquisition module, $\mathbf{g}$ T1: brad and spur drill, and $\mathbf{h} \mathrm{T} 2$ : fishtail twist drill

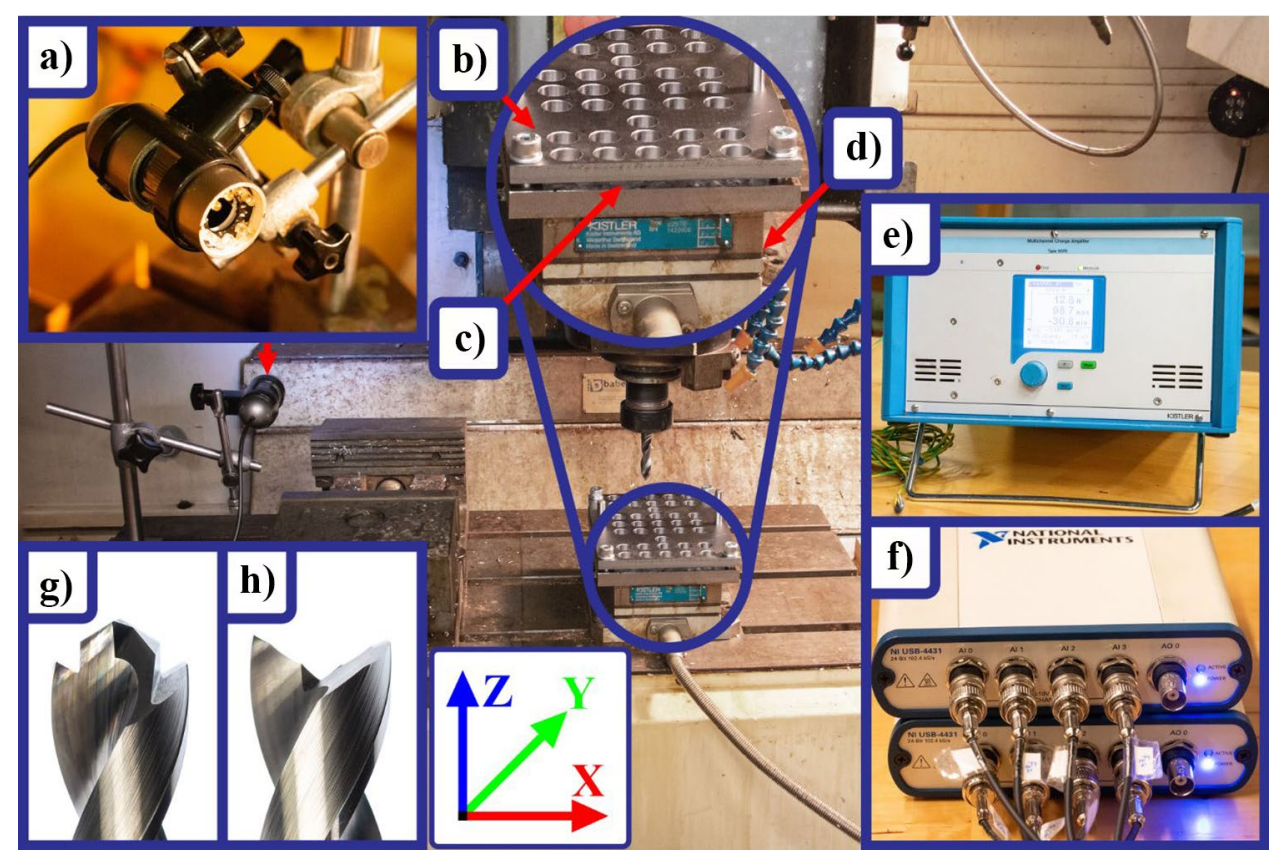


Table 3 Factors and their levels

\begin{tabular}{|c|c|c|c|c|c|c|c|c|}
\hline \multirow[t]{2}{*}{ Factors } & & & \multicolumn{3}{|c|}{ Levels } & \multirow[b]{2}{*}{4} & \multirow[b]{2}{*}{5} & \multirow[b]{2}{*}{6} \\
\hline & & & 1 & 2 & 3 & & & \\
\hline Tool geometry & $T$ & - & $\mathrm{T} 1$ & $\mathrm{~T} 2$ & & & & \\
\hline Feed & $f$ & $\mathrm{~mm} / \mathrm{rev}$ & 0.15 & 0.25 & 0.35 & & & \\
\hline Material & $M$ & - & VA & VB & $\mathrm{VC}$ & RA & RB & $\mathrm{RC}$ \\
\hline
\end{tabular}

status, which also correlates with the kinematic characteristics of the drilling process [30]. While the cutting resistance of the material remains quasi-consistent during drilling, an increase in tool wear can result in increased thrust force and torque and vice versa [10]. Therefore, to exclude or compensate the effect of tool wear on the output parameters, we monitored the tool condition and evaluated it through digital image processing. Results show that tool wear is not considerable; therefore, the measured values were not compensated for.

\subsection{Analysis and discussion of thrust force}

Representative thrust force diagrams can be seen in Fig. 4a, $\mathrm{c}$ for the tools $\mathrm{T} 1$ and $\mathrm{T} 2$, respectively. The force diagrams can be divided into different sections highlighted by different colours, corresponding to the drilling workflow steps illustrated in Fig. 4b, d. As the geometry of T1 is more complex than the geometry of $\mathrm{T} 2$, its response characteristics can be separated into more sections $(S)$. The first section $\left(S_{1}\right)$ of Fig. 4a corresponds to the relatively large energy need of entering the chisel edge into the composite, which results in a significant compression-dominated thrust force until $S_{6}$ (the chisel edge exits the composite). When the hole exit surface and the edge are machined, the awaking thrust forces are relatively small, which is advantageous from the point of view of burr and delamination. This advantageous phenomenon of brad and spur type drills is explained effectively by the "cut first and push second" effect, according to Su et al. [31]. In contrast to the relatively large forces generated by the chisel edge of $\mathrm{T} 1$, taking into account that $\mathrm{T} 2$ does not have a chisel edge, drilling using T2 requires less energy. The largest thrust force is in $S_{4}-S_{5}$ and $S_{2}$ in the case of T1 and $\mathrm{T} 2$, respectively, due to the most extended contact length between the drilling tools and CFRPs, which result in the larger chip cross-sections.

The representative graphs in Fig. 4 indicate that tool geometry has the most significant influence on the thrust force. The thrust force generated by $\mathrm{T} 1$ is higher than that of $\mathrm{T} 2$, which suggests that the risk of push-out delamination is higher in the case of T1. Nevertheless, T2 generated a considerable negative thrust force at the beginning of the first section, resulting in a higher risk of peel-up delamination at the entry of the hole. Although the scope of the present paper does not extend to the analysis of delamination, its investigation is essential in the future.

The influences of the virgin and recycled CFRPs and feed on the thrust force in each applied cutting tool can be seen in Fig. 5. Beyond that, it is clear from the diagrams that the thrust force is definitely smaller for $\mathrm{T} 2$; the interaction between the cutting tools ( $\mathrm{T} 1$ and $\mathrm{T} 2$ ) and the reinforcing structures (VA, RA, VB, RB, VC, RC) is significant. On the one hand, the influence of reinforcing structures on the thrust force does not seem consistent in the case of T2. On the other hand, in the case of T1, (i) each recycled CFRP required higher thrust forces than the virgin CFRP, (ii) the

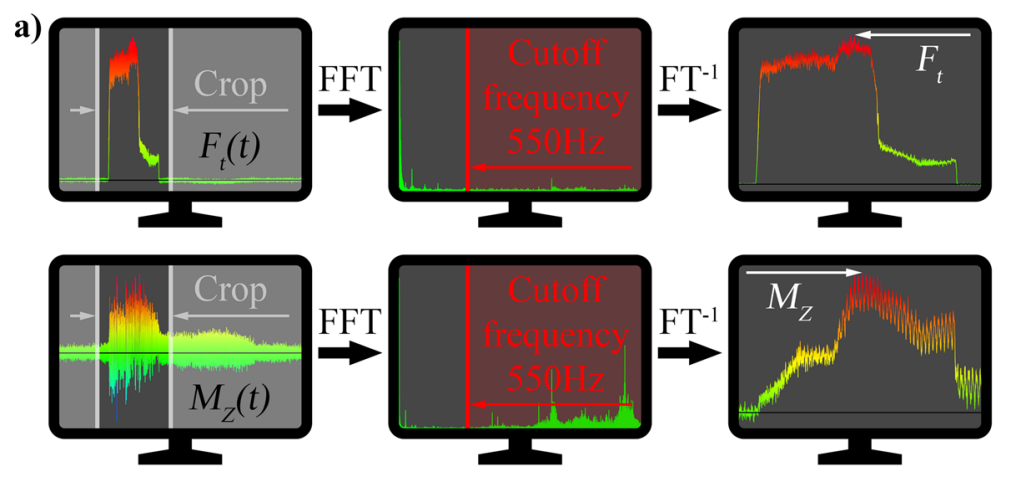

b)

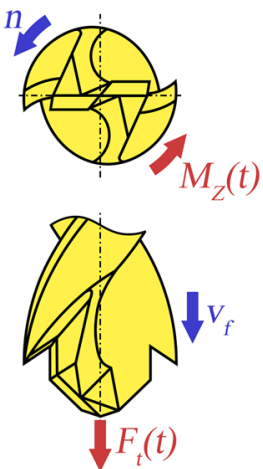

c)

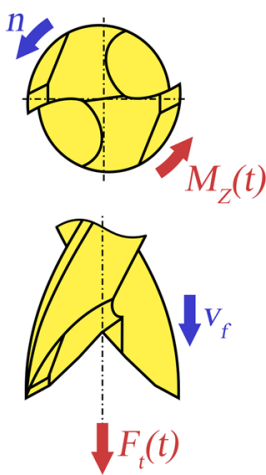

Fig. 3 a A schematic of the workflow to generate output parameters $F_{t}(\mathrm{~N})$ and $M_{z}(\mathrm{Nm})$ and their interpretation at the applied $\mathbf{b}$ brad and spur and $\mathbf{c}$ fishtail twist drills 

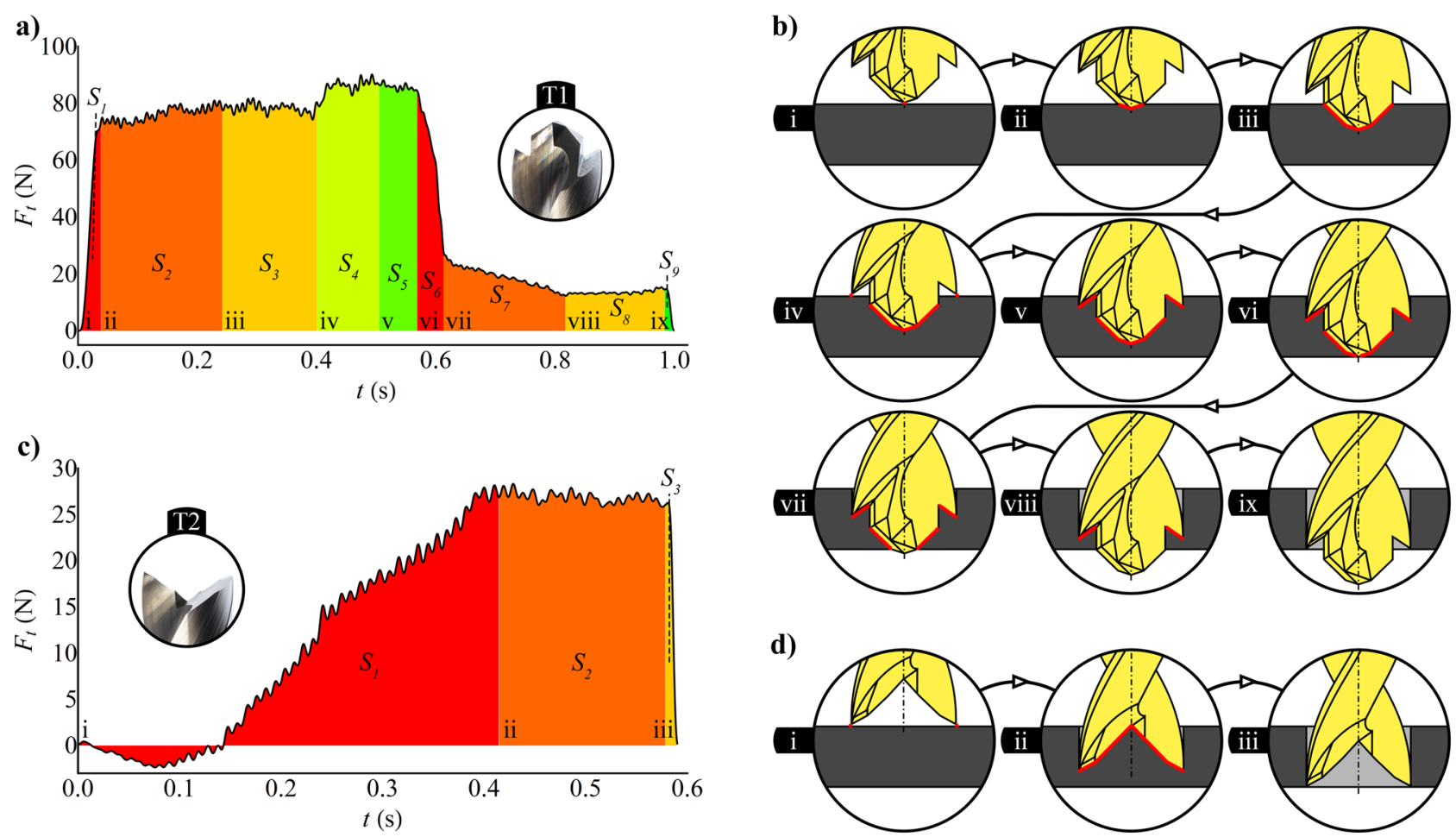

Fig. 4 Representative cutting force diagrams and the schematics of drilling steps: a T1 thrust force, $\mathbf{b}$ T1 drilling steps, $\mathbf{c}$ T2 thrust force, and d T2 drilling steps

influence of feed is clear and significant, and (iii) the milled CFRPs required the highest thrust force, followed by the chopped CFRPs and the nonwoven mat CFRPs.

It is well known that (i) the shorter the reinforcing fibre than the critical fibre length, the higher the risk of fibre pullout formation, and (ii) fibre pull-out formation requires less energy than cutting or crushing fibres. Therefore, the milled CFRP was expected to have the smallest cutting force than the more extended reinforcing structures (e.g., continuous fibres). However, the reinforcement structure (orientations and positions of fibres) seems to have a more significant influence on the cutting force than the fibre length. Figure 6 illustrates the different reinforcing structures applied in this research. In addition to the significant differences in fibre length, the orientations and positions of the fibres are significantly different in each reinforcing structure: (i) the chopped fibres are locally arranged (fibres are arranged into fibre groups), but these fibre groups are quasi-randomly oriented in the section $X Y$ as it is illustrated in Fig. 6b; (ii) the positions of nonwoven mat fibres
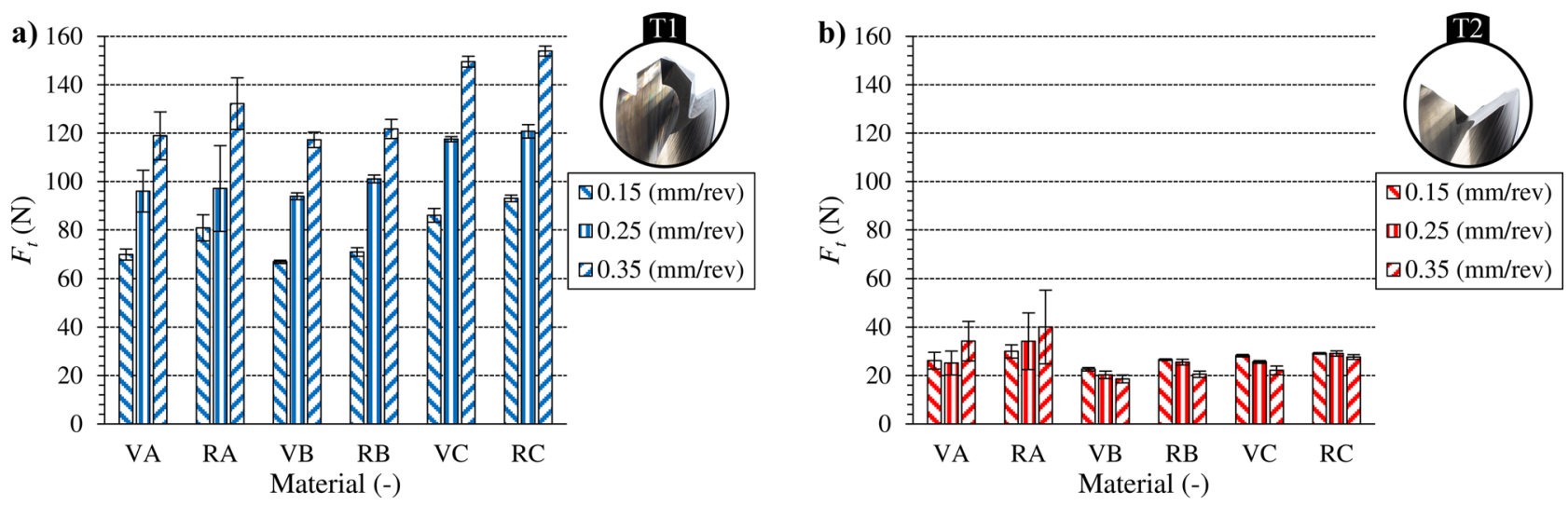

Fig. 5 The influence of material and feed on the thrust force with a the T1 and $\mathbf{b}$ the T2 drilling tools 
a)
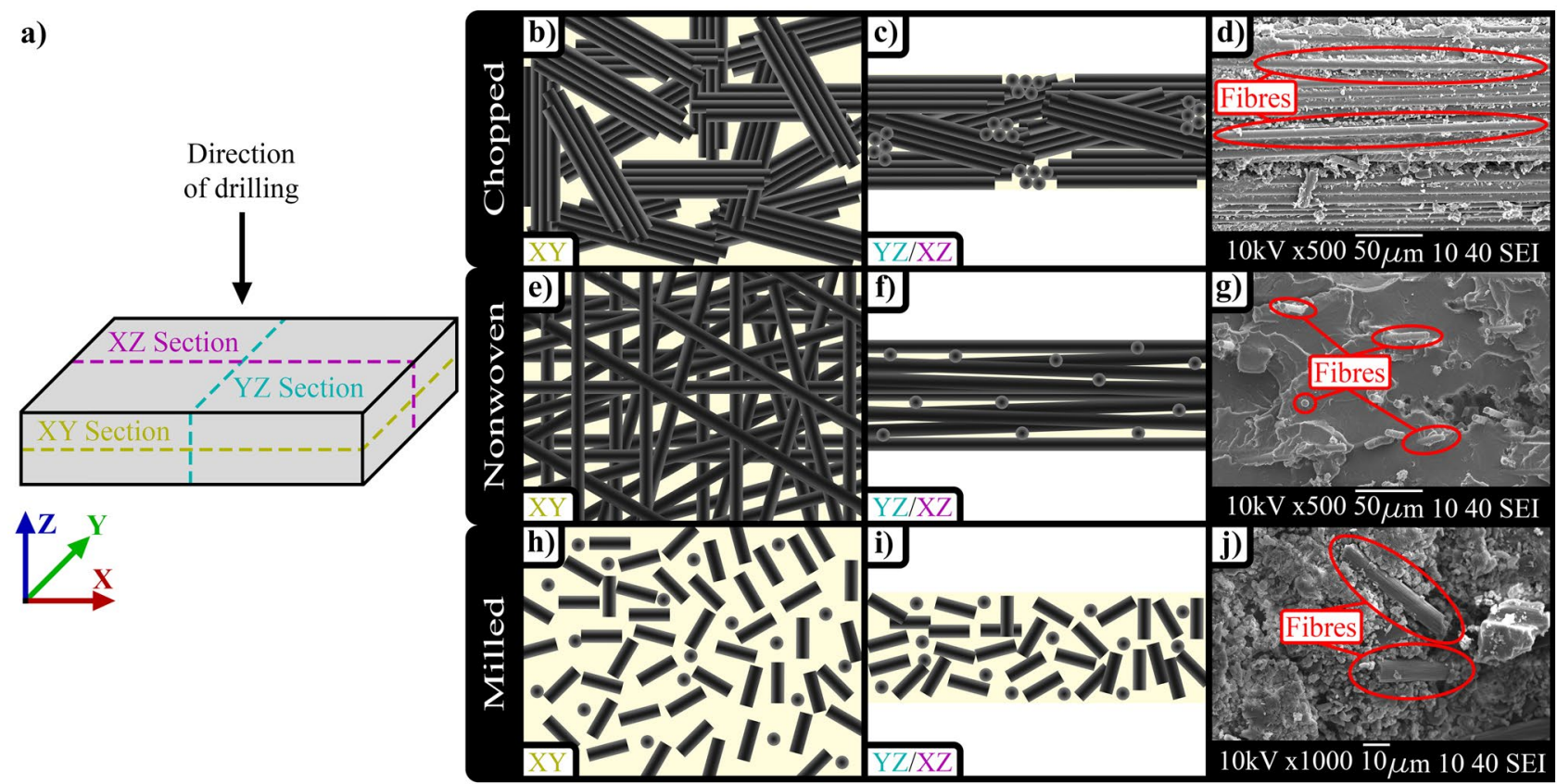

Fig. 6 Schematic illustrations of different reinforcing structures: a CFRP specimen, b-d sections of chopped reinforced CFRP, e-g sections of nonwoven mat reinforced CFRP, and $\mathbf{h}-\mathbf{j}$ sections of milled reinforced CFRP

are arranged but their orientations are quasi-randomised as illustrated in Fig. 6e-g; and (iii) both the orientations and positions of the milled fibres are quasi-random as illustrated in Fig. 6h-j. Taking into account that (i) in the case of the milled CFRP, the probability that one single fibre is oriented parallel to the loading direction (along the axes $Z$ ) is large, and (ii) the fibre strength along the fibre length is more times larger than in the radial direction; the milled CFRP structure requires more energy — and thus cutting force — than the other structures.

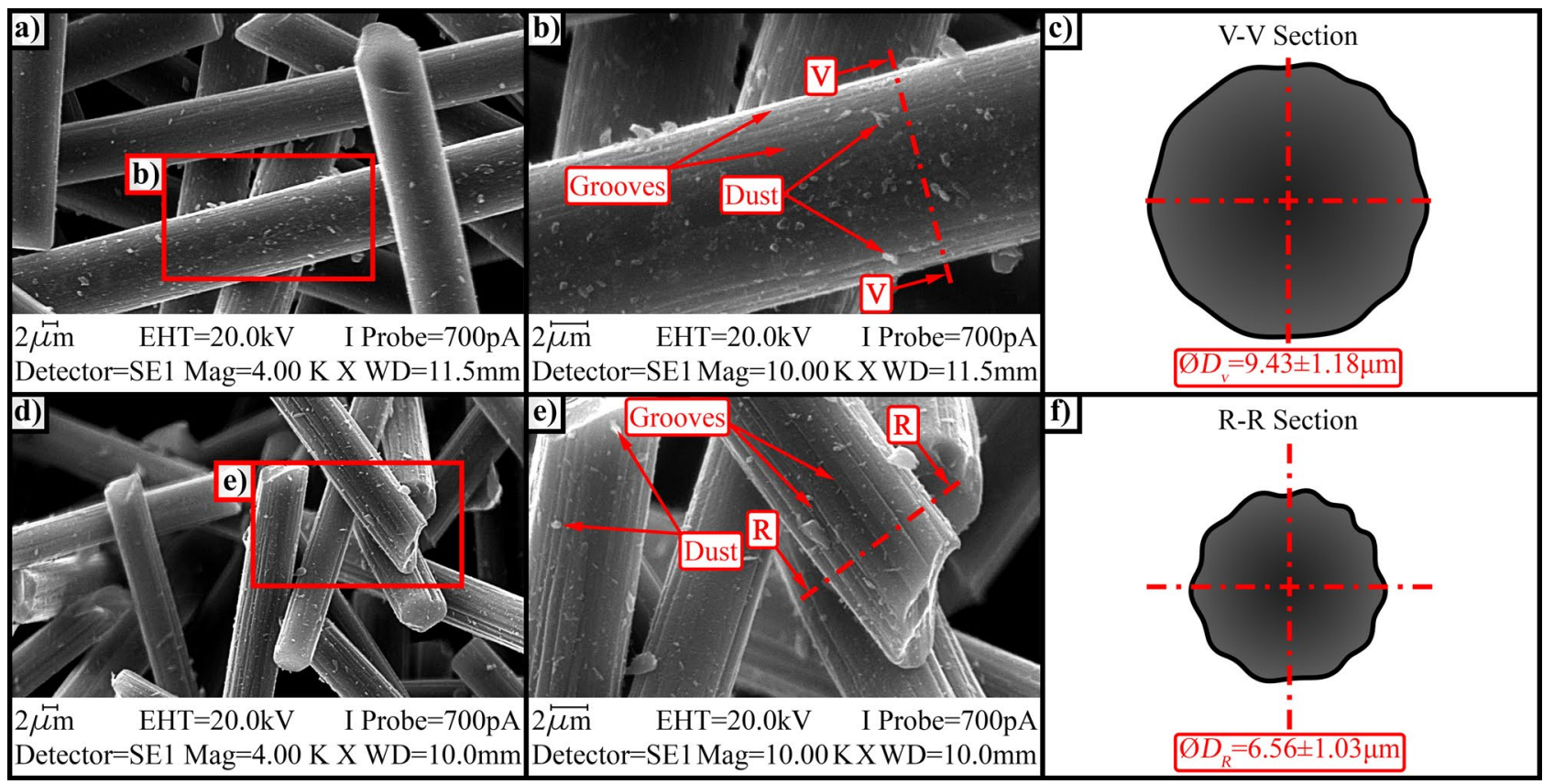

Fig. 7 Representative SEM images of a, b virgin milled carbon fibres and a $\mathbf{c}$ schematic cross-section of a single virgin milled fibre; d, e recycled milled carbon fibres and a $\mathbf{f}$ schematic cross-section of a single recycled milled fibre 
Table 4 The analysis of variance (ANOVA) table for the thrust force $\left(F_{t}\right)$ in CFRPs

\begin{tabular}{llllrl}
\hline Source & DF & Adj SS & Adj MS & F-value & P-value \\
\hline Model & 11 & $3,18,653$ & 28,968 & 248.46 & 0.000 \\
Linear & 4 & 296,452 & 74,113 & 635.67 & 0.000 \\
$T(-)$ & 1 & 272,972 & 272,972 & 2341.31 & 0.000 \\
$f(\mathrm{~mm} / \mathrm{rev})$ & 2 & 22,215 & 11,108 & 95.27 & 0.000 \\
$R / V(-)$ & 1 & 1265 & 1265 & 10.85 & 0.001 \\
2-Way Interactions & 5 & 22,114 & 4423 & 37.93 & 0.000 \\
$T \cdot f$ & 2 & 22,070 & 11,035 & 94.65 & 0.000 \\
$T \cdot R / V$ & 1 & 35 & 35 & 0.30 & 0.585 \\
$f \cdot R / V$ & 2 & 9 & 4 & 0.04 & 0.963 \\
3 -way interactions & 2 & 87 & 43 & 0.37 & 0.690 \\
$T \cdot f \cdot R / V$ & 2 & 87 & 43 & 0.37 & \\
Error & 168 & 19,587 & 117 & & \\
\hline
\end{tabular}

The main effect plot diagrams of tool, recycled/virgin status (R/V status), and feed factors on the thrust force can be seen in Fig. 8. According to the diagrams and the ANOVA table (Table 4), all the analysed factors have a statistically significant influence on the thrust force at a significance level of $p=0.05$. Tool type has the most significant influence on the thrust force, followed by feed and recycled/virgin status. The ANOVA results concerning the impact of the tool on the force correlate with the physical aspects of machining: higher chisel edge and higher point angles result in a higher thrust force. Therefore, cutting with $\mathrm{T} 2$ requires less energy than cutting with $\mathrm{T} 1$. As we expected based on a previous study, the higher the feed, the higher the force, due to the larger chip cross-section [32].

Nevertheless, it has to be pointed out that "the higher the feed, the higher the force" is valid only if the specific cutting force is constant. In machining inhomogeneous and anisotropic materials like CFRP composites, the specific cutting force is highly affected not only by chip thickness, as pointed out by Biró and Szalay [33], but also by fibre orientation [34]. Considering that the positions and orientations of fibre reinforcements are stochastic, the influence of feed on the thrust force is not evident in fibre-reinforced polymer composites.

The ANOVA results show that the recycled/virgin status of the applied CFRPs significantly influences the thrust force in each CFRP. The thrust force is slightly but measurably higher $(\sim 8 \%)$ in the rCFRPs than in the virgin CFRP composites. The experiments indicate that the main effect of whether the reinforcement is recycled or virgin is $5.3 \mathrm{~N}$, which may lead to a higher risk of delamination and faster tool wear compared to virgin CFRPs. The reason why the thrust forces in rCFRPs are larger than in virgin CFRPs was explored by analysing single milled carbon fibres with a JEOL JSM 6380LA scanning electron microscope. Representative images of virgin and recycled milled carbon fibres can be seen in Fig. 7a, b, d, e, respectively. Two main differences were observed which may significantly influence the energy demand of cutting: (i) the longitudinal grooves in the recycled fibres are deeper than those in virgin fibres, and (ii) the average diameter of recycled milled fibres $\left(d_{r}=6.57 \pm 1.03 \mu \mathrm{m}\right)$ is smaller than that of virgin fibres $\left(d_{v}=9.44 \pm 1.19 \mu \mathrm{m}\right)$. The longitudinal grooves on the recycled milled fibres are possibly deepened by the thermochemical degradation during pyrolysis [35]. As smaller fibre diameter and deeper grooves result in a larger specific contact area between fibres and resin, considering similar adhesion and impregnation quality, the resultant strength of rCFRPs is larger. This is also confirmed by the material testing results (flexural strength and interlaminar shear strength) in Table 2. Thus, with the application of the same resin, the cutting demand of the recycled CFRPs is larger than that of virgin CFRPs.

The single-fibre characteristics of chopped and nonwoven mat structures were also investigated through scanning electron microscopy. The surface characteristics
Fig. 8 Main effect plots for thrust force $\left(F_{t}\right)$ at a significance level of $p=0.05$ : a tool vs mean of the thrust force, $\mathbf{b}$ recycled/ virgin status vs mean of the thrust force, and $\mathbf{c}$ feed vs mean of the thrust force

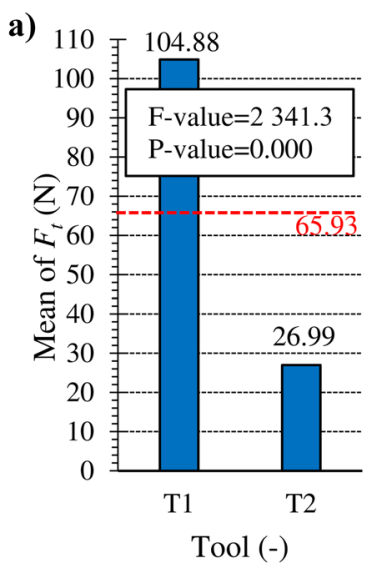

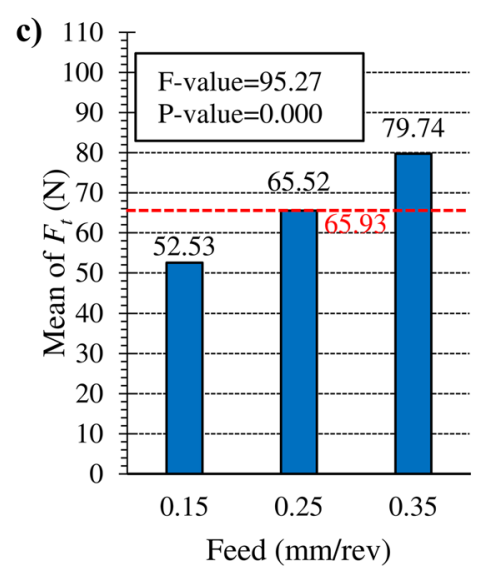


Fig. 9 Interaction plots for thrust force $\left(F_{t}\right)$ at a significance level of $p=0.05$ : a feed and tools, $\mathbf{b}$ recycled/virgin status and tool, and $\mathbf{c}$ recycled/virgin status and feed

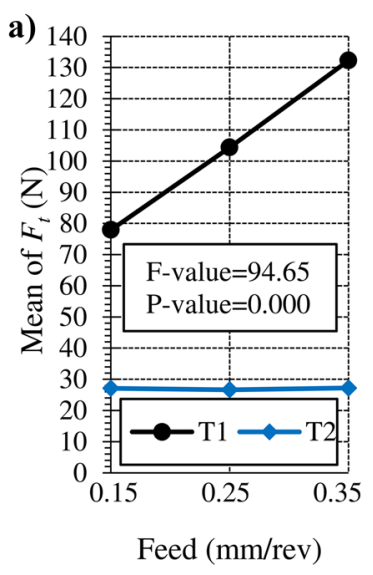

of single recycled fibres in the nonwoven mat structure were similar to those of virgin fibres, but there was a significant difference in fibre diameter. The average diameter of recycled fibres in the nonwoven mat structure was $d_{r}=5.24 \pm 0.14 \mu \mathrm{m}$, that is, significantly smaller than that of virgin fibres $\left(d_{v}=13.38 \pm 0.20 \mu \mathrm{m}\right)$. In contrast, there was no significant difference in the surface characteristics and diameter of the single fibres in the recycled and virgin chopped tows.

Although the larger resultant strengths of rCFRPs are advantageous from the point of view of their applications,
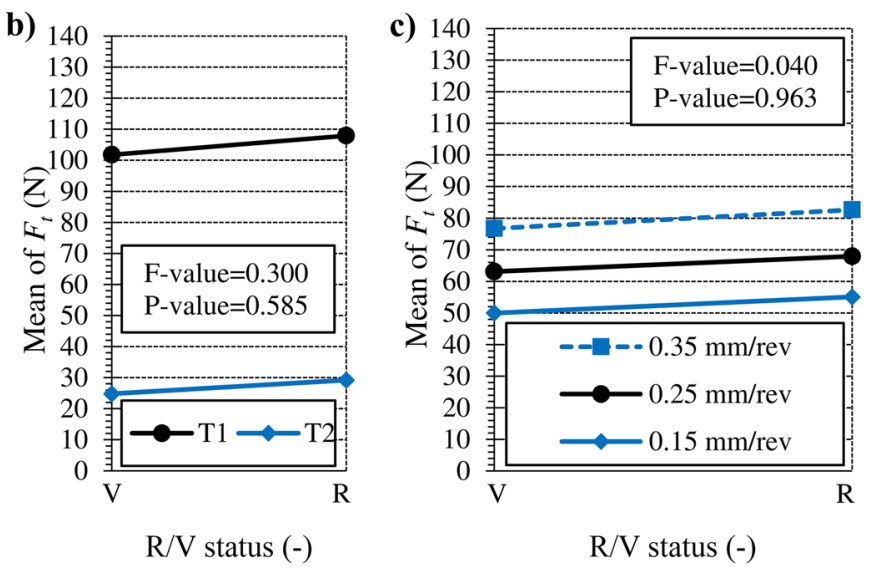

it makes cutting them more challenging. Furthermore, considering that rCFRPs increase sustainability, rCFRPs are expected to be an excellent alternative to virgin CFRPs (Fig. 8).

The interaction effects of the analysed factors are illustrated in Fig. 9 and Table 4. The two-way interaction between the tool and feed is significant, which means that the influence characteristic of feed depends on the applied cutting tool and vice versa. The other two-way $(T-R / V$ and $R / V-f)$ and three-way $(T-R / V-f)$ interaction terms are not considerable. Therefore, we recommend that the drilling process
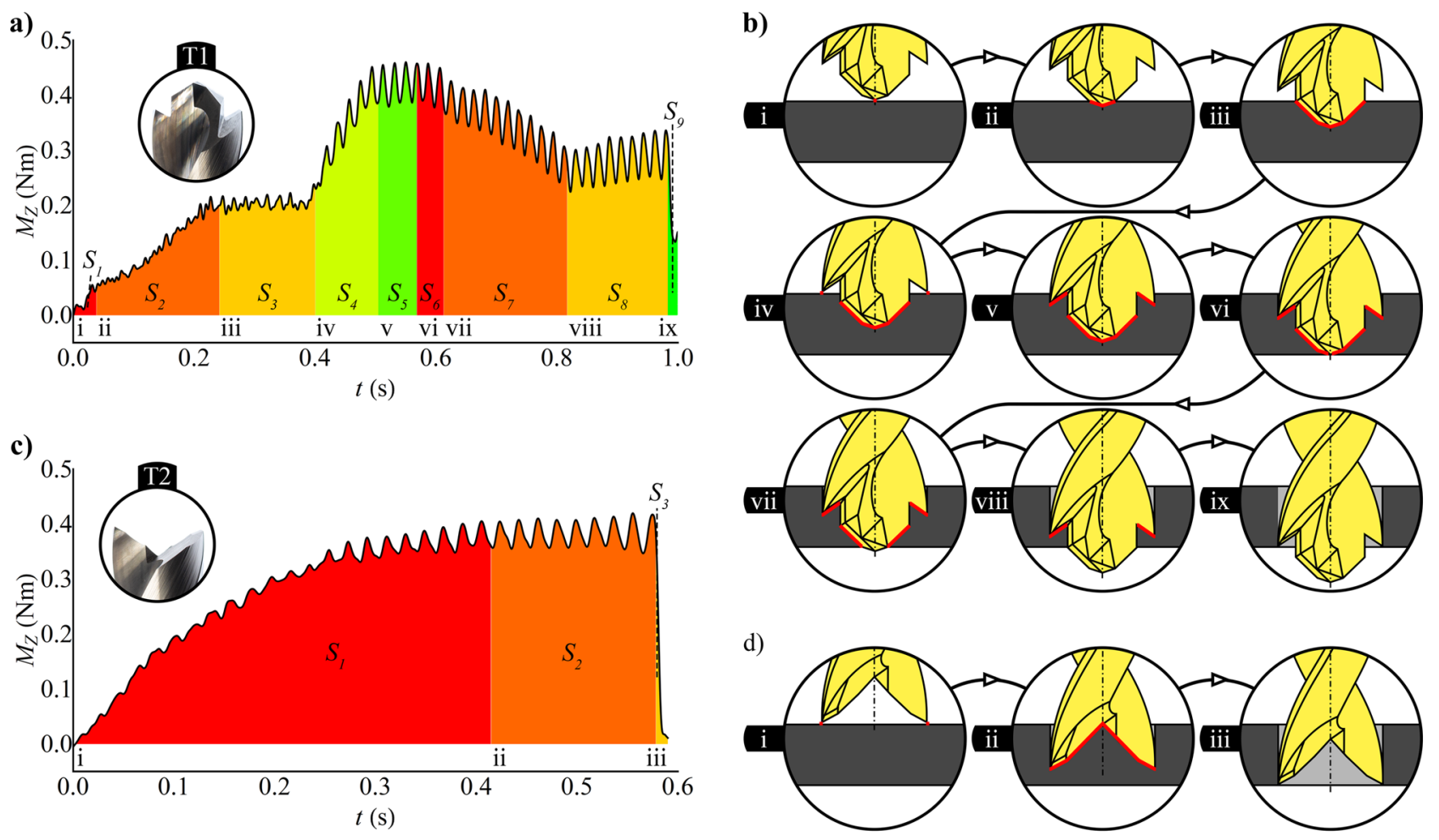

Fig. 10 Representative drilling torque diagrams and the schematic of drilling steps: a T1 drilling torque, b T1 drilling steps, $\mathbf{c}$ T2 drilling torque, and d T2 drilling steps 
in recycled CFRPs is optimised first by the proper selection of cutting tool, then the proper setting of feed.

\subsection{Analysis and discussion of drilling torque}

Representative drilling torque diagrams can be seen in Fig. 10a, c, for the tools T1 and T2, respectively. Similarly, as the thrust force diagrams, the torque diagrams are also divided into different sections highlighted by different colours, which correspond to the drilling workflow steps illustrated in Fig. 10b, d. As the largest chip cross-sections resulted in the largest thrust forces in $S_{4}-S_{5}$ and $S_{2}$ in the case of $\mathrm{T} 1$ and $\mathrm{T} 2$, respectively, the highest drilling torques were measured in the same sections.

The maximum values of the drilling torque of $\mathrm{T} 1$ and $\mathrm{T} 2 \mathrm{do}$ not differ significantly. Despite the thrust force being mainly affected by the chisel geometry of the cutting tool, the torque is affected mainly by the cutting edge radius and the rake angle due to their direct effect on the chip removal mechanisms and, therefore, on the $F_{x}$ and $F_{y}$ force components [36]. Considering that the rake angles $\left(\gamma_{T 1}=30^{\circ} \pm \delta^{\circ}, \gamma_{T 2}=30^{\circ} \pm \delta^{\circ}\right)$ and the cuttingedge radiuses $\left(r_{\beta} \rightarrow 0 \mathrm{~mm}\right)$ are similar for each applied tool, we did not expect torque maximums to differ considerably. Indeed, they do not differ in maximums, but the torque diagrams differ in nature due to the different complexity of the cutting tools.

The influences of the virgin and recycled CFRPs and feed on the drilling torque in each applied cutting tool can be seen in Fig. 11. Despite a significant interaction between the cutting tool and reinforcing structures on the thrust force (in Fig. 6), the influences of reinforcing structure and feed seem consistent in each cutting tool: (i) the higher the feed, the higher the drilling torque in each structure and (ii) the drilling of milled CFRPs required the largest torques, followed by the chopped CFRPs and nonwoven mat CFRPs, respectively. The possible reason for higher torque in milled CFRPs is similar to the reason for higher thrust forces, as discussed earlier.

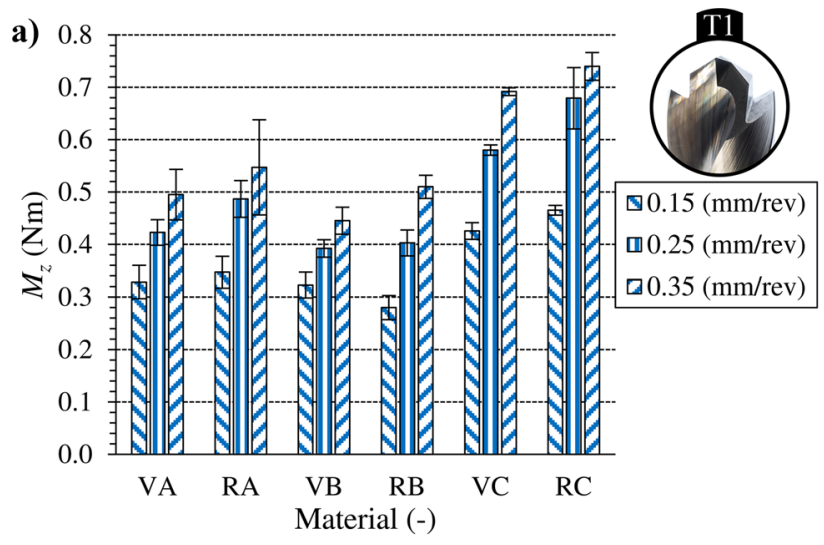

Table 5 The analysis of variance (ANOVA) table for the drilling torque $\left(M_{z}\right)$ in CFRPs

\begin{tabular}{llllll}
\hline Source & DF & Adj SS & Adj MS & $\boldsymbol{F}$-value & $\boldsymbol{P}$-value \\
\hline Model & 11 & 1.37590 & 0.125082 & 12.64 & 0.000 \\
Linear & 4 & 1.34346 & 0.335866 & 33.94 & 0.000 \\
$T(-)$ & 1 & 0.03424 & 0.034238 & 3.46 & 0.065 \\
$f(\mathrm{~mm} / \mathrm{rev})$ & 2 & 1.20189 & 0.600943 & 60.73 & 0.000 \\
$R / V(-)$ & 1 & 0.10734 & 0.107339 & 10.85 & 0.001 \\
2 -way interactions & 5 & 0.03075 & 0.006151 & 0.62 & 0.684 \\
$T \cdot f$ & 2 & 0.00539 & 0.002696 & 0.27 & 0.762 \\
$T \cdot R / V$ & 1 & 0.00405 & 0.004052 & 0.41 & 0.523 \\
$f \cdot R / V$ & 2 & 0.02131 & 0.010654 & 1.08 & 0.343 \\
3 -way interactions & 2 & 0.00169 & 0.000843 & 0.09 & 0.918 \\
$T \cdot f \cdot R / V$ & 2 & 0.00169 & 0.000843 & 0.09 & 0.918 \\
Error & 168 & 1.66247 & 0.009896 & & \\
Model & 179 & 3.03837 & & & \\
\hline & & & & & \\
\hline
\end{tabular}

Drilling torque $\left(M_{z}\right)$ was measured through the $X$ and $Y$ sensors of the KISTLER dynamometer, so torque correlates to the $F_{x}$ and $F_{y}$ cutting force components. Although the thrust force (which is equivalent to the $F_{z}$ cutting force component) is significantly affected by the geometry of the cutting tool, drilling torque is independent of drill geometry, as can be seen in the ANOVA table in Table 5. As chip crosssection is identical in each drilling tool geometries, torque is not expected to differ significantly. According to the main effect plots in Fig. 12 and the ANOVA table in Table 5, the feed has the most significant statistical and physical influence on drilling torque in each CFRP composite, followed by R/V status. Similarly to the previously discussed thrust force in CFRPs, the higher the feed, the higher the chip cross-section, which results in higher $F_{x}$ and $F_{y}$ cutting force components and in higher torque, as also observed by Abhishek et al. [37].

The ANOVA results show that the recycled/virgin status of CFRPs plays a significant role in determining drilling

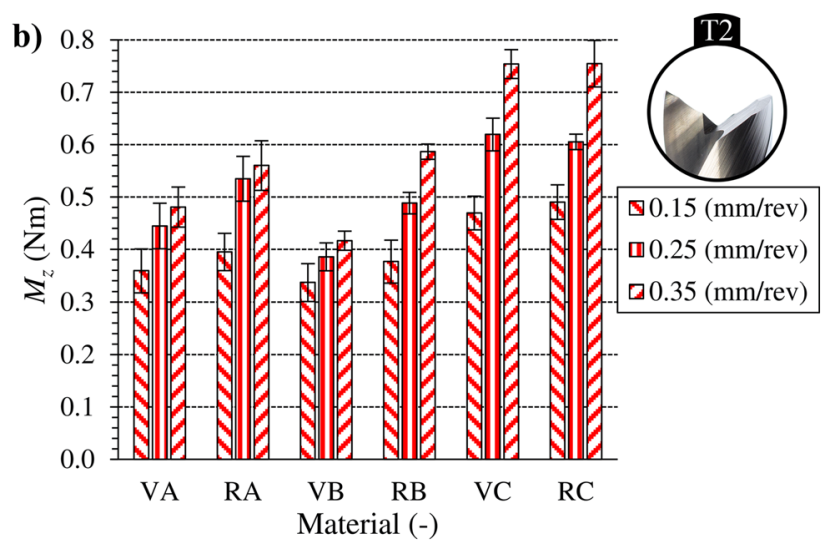

Fig. 11 The influence of material and feed on the drilling torque with the use of a T1 and b T2 drilling tools 
Fig. 12 Main effect plots for drilling torque $\left(M_{z}\right)$ at a significance level of $p=0.05$ : a tool vs mean of the drilling torque, b recycled/virgin status vs mean vs mean of the drilling torque of the drilling torque, and $\mathbf{c}$ feed
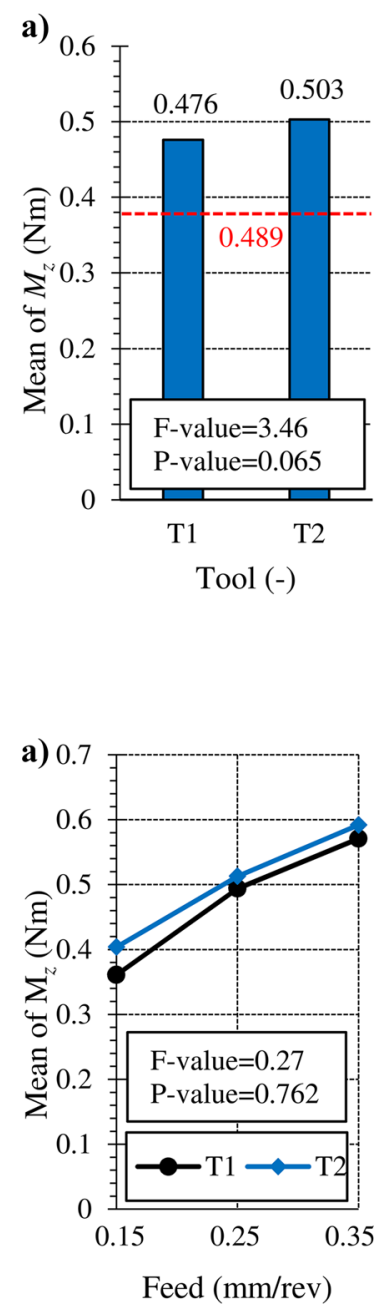

Fig. 13 Interaction plots for drilling torque $\left(M_{z}\right)$ at a significance level of $p=0.05$ : a feed and tools, $\mathbf{b}$ recycled/virgin status and tool, and c recycled/ virgin status and feed
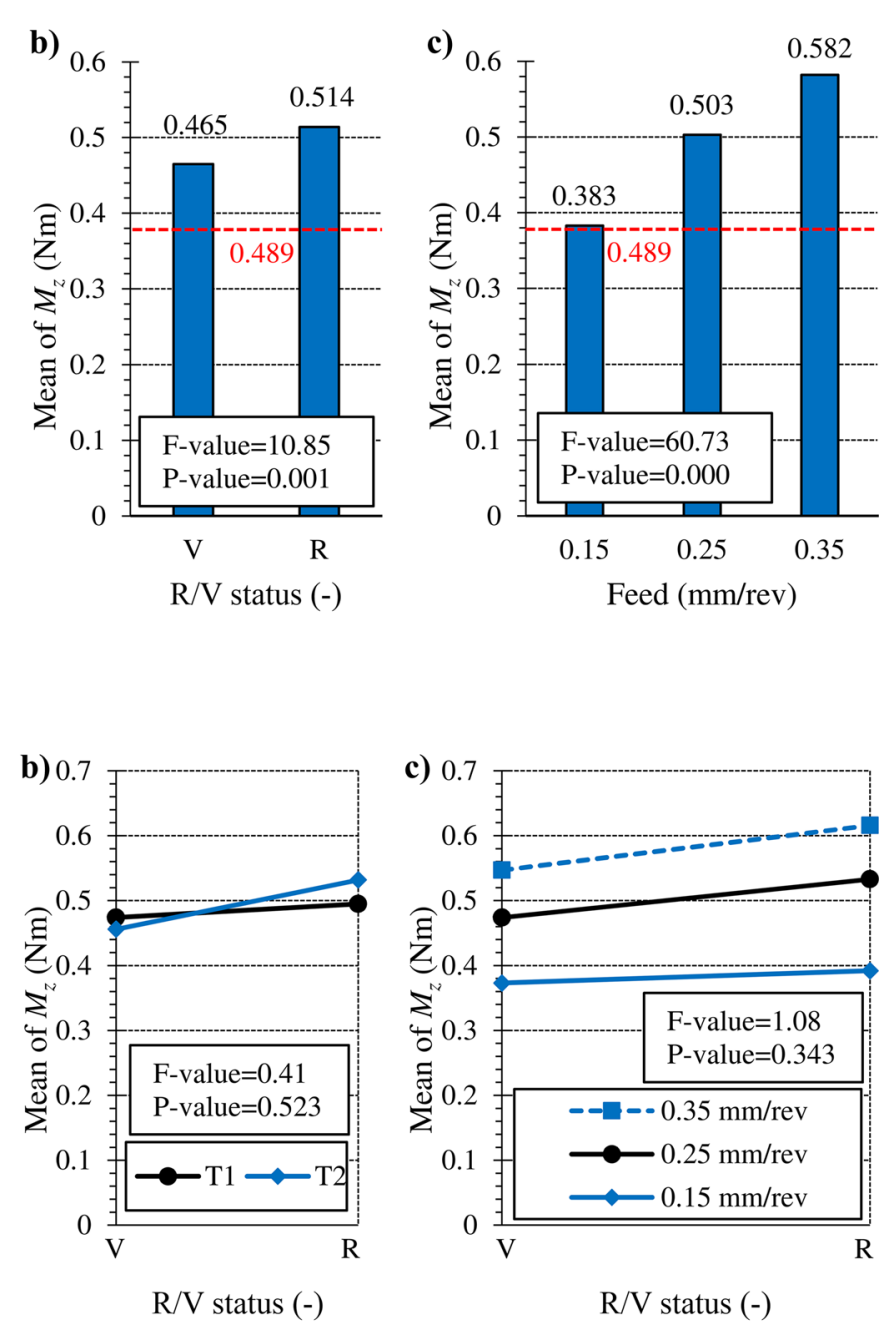

torque, as was expected from the results of material testing. As with thrust force, drilling torque is higher $(\sim 11 \%)$ in recycled CFRPs than in virgin CFRPs. While the higher compression strength of rCFRPs may explain the higher thrust force, the higher torque can be explained by the higher interlaminar shear strength of the rCFRPs than that of the virgin CFRPs. Despite the statistically higher drilling torque in rCFRPs than in virgin CFRPs, the main effect of the recycled/virgin status on $M_{z}$ is only $0.049 \mathrm{Nm}$, representing only a small increase in the risk of drillinginduced geometrical defect, e.g., delamination, fibre pullout, matrix smearing, or burrs. However, we recommend that thrust force and drilling torque should be minimised in rCFRPs.

The interaction terms of the analysed factors are not significant on drilling torque, as shown in Fig. 13 and Table 5. Therefore, for the optimisation of drilling torque in CFRPs, we recommend that feed is optimised first, as it is the most robust factor, and then the proper selection of recycled/virgin carbon fibres.
Although the results suggest that both thrust force and drilling torque are greater in each analysed recycled CFRP than in the virgin CFRPs, we recommend future research on the comparative chip removal mechanisms of rCFRPs and virgin CFRPs, to model and explain the differences in machining recycled and virgin CFRPs in more detail.

\section{Conclusions}

Drilling experiments were conducted in virgin and recycled chopped tow, nonwoven mat, and milled carbon fibre-reinforced polymer composites at different feeds using different cutting tools. The thrust force and drilling torque were analysed and compared in virgin and recycled CFRPs through ANOVA at a significance level of 0.05 . Based on the results, the following conclusions can be drawn:

- The ANOVA results show that tool type has the most significant influence on the thrust force, followed by 
feed and recycled/virgin status. The fishtail twist drill required significantly less thrust force than the brad and spur drill. Furthermore, the thrust force is slightly higher (8\%) in rCFRPs than in virgin CFRP composites. The two-way interaction between the tool and feed was found significant; therefore, we recommend optimising the drilling process in recycled CFRPs by the proper setting of feed using a solid carbide drill having "cut first and push second" effect without a chisel edge.

- It was observed that the milled CFRPs requires the highest thrust force and drilling torque, followed by the chopped and the nonwoven mat CFRPs, respectively. The milled CFRP structure required more energy because the probability that one single fibre is oriented parallel to the loading direction (along the axes $Z$ ) is large, and the fibre strength along the fibre length is more times larger than in the radial direction.

- The feed has the most significant statistical and physical influence on drilling torque in each CFRP composite, followed by recycled/virgin status, while the influence of tool geometry is not considerable. Although the effect of recycled/virgin status is significant, the drilling torque is slightly higher $(11 \%)$ in rCFRPs than in virgin CFRP composites. The interaction terms of the analysed factors do not significantly affect drilling torque.

- Although rCFRPs are expected to be an excellent alternative to virgin CFRPs, a comparative analysis of chip removal mechanisms in recycled and virgin CFRPs is recommended in the future to model and explain the differences in machining recycled and virgin CFRPs in detail.

Acknowledgements This research was implemented, thanks to the support of the 2019-2.1.11-TÉT-2020-00203 project, which encourages scientific and technological cooperation between China and Hungary. The authors acknowledge the support of Péter Sántha and Dóra Károly in experimental work.

Author contribution Norbert Geier: conceptualisation, methodology, writing - original draft, supervision; Dániel István Poór: resources, formal analysis, investigation; Csongor Pereszlai: visualisation, software, writing — review and editing; Péter Tamás-Bényei: resources, writing — original draft; Jinyang Xu: writing — review and editing.

Funding Open access funding provided by Budapest University of Technology and Economics. This research was partly supported by the National Research, Development and Innovation Office (NKFIH) No. OTKA-PD20-134430 and ÚNKP-21-5-BME-370 New National Excellence Program of the Ministry for Innovation and Technology, and by the Janos Bolyai Research Scholarship of the Hungarian Academy of Sciences No. BO/00658/21/6. The research reported in this paper and carried out at BME has been partly supported by the NRDI Fund (TKP2020 NC, Grant No. BME-NC) based on the charter of bolster issued by the NRDI Office under the auspices of the Ministry for Innovation.

\section{Declarations}

Ethics approval Not applicable.

Consent to participate Not applicable.

Consent for publication Not applicable.

Conflict of interest Not applicable.

Open Access This article is licensed under a Creative Commons Attribution 4.0 International License, which permits use, sharing, adaptation, distribution and reproduction in any medium or format, as long as you give appropriate credit to the original author(s) and the source, provide a link to the Creative Commons licence, and indicate if changes were made. The images or other third party material in this article are included in the article's Creative Commons licence, unless indicated otherwise in a credit line to the material. If material is not included in the article's Creative Commons licence and your intended use is not permitted by statutory regulation or exceeds the permitted use, you will need to obtain permission directly from the copyright holder. To view a copy of this licence, visit http://creativecommons.org/licenses/by/4.0/.

\section{References}

1. Geier N, Paulo Davim J, Szalay T (2019) Advanced cutting tools and technologies for drilling carbon fibre reinforced polymer (CFRP) composites: a review. Compos Part A 125:105552. https:// doi.org/10.1016/j.compositesa.2019.105552

2. Aamir M, Tolouei-Rad M, Giasin K, Nosrati A (2019) Recent advances in drilling of carbon fiber-reinforced polymers for aerospace applications: a review. Int J Adv Manuf Technol 105:22892308. https://doi.org/10.1007/s00170-019-04348-z

3. May D, Goergen C, Friedrich K (2021) Multifunctionality of polymer composites based on recycled carbon fibers: a review. Adv Ind Eng Polym Res. https://doi.org/10.1016/j.aiepr.2021.01.001

4. Balaji AB, Rudd C, Liu X (2020) Recycled carbon fibers (rCF) in automobiles: towards circular economy. Mater Circ Econ 2:4. https://doi.org/10.1007/s42824-020-00004-0

5. Zhang J, Chevali VS, Wang H, Wang C-H (2020) Current status of carbon fibre and carbon fibre composites recycling. Compos Part B Eng 193:108053. https://doi.org/10.1016/j.compositesb.2020.108053

6. Karuppannan Gopalraj S, Kärki T (2020) A review on the recycling of waste carbon fibre/glass fibre-reinforced composites: fibre recovery, properties and life-cycle analysis. SN Appl Sci 2:433. https://doi.org/10.1007/s42452-020-2195-4

7. Pimenta S, Pinho ST (2014) The influence of micromechanical properties and reinforcement architecture on the mechanical response of recycled composites. Compos Part Appl Sci Manuf 56:213-225. https://doi.org/10.1016/j.compositesa.2013.10.013

8. van de Werken N, Reese MS, Taha MR, Tehrani M (2019) Investigating the effects of fiber surface treatment and alignment on mechanical properties of recycled carbon fiber composites. Compos Part Appl Sci Manuf 119:38-47. https://doi.org/10.1016/j. compositesa.2019.01.012

9. Genna S, Papa I, Lopresto V, Tagliaferri V (2020) Mechanical characterisation of CFRP laminates with recycled carbon fiber obtained by resin infusion under Flexible Tooling (RIFT) technology. Compos Sci Technol 199:108328. https://doi.org/10.1016/j. compscitech.2020.108328

10. Xu W, Zhang L (2018) Tool wear and its effect on the surface integrity in the machining of fibre-reinforced polymer composites. 
Compos Struct 188:257-265. https://doi.org/10.1016/j.compstruct. 2018.01.018

11. Bai Y, Jia Z, Fu R et al (2021) Mechanical model for predicting thrust force with tool wear effects in drilling of unidirectional CFRP. Compos Struct 262:113601. https://doi.org/10.1016/j. compstruct.2021.113601

12. Ahmad J (2009) Machining of polymer composites. Springer, US

13. Franke V (2011) Drilling of long fiber reinforced thermoplasticsinfluence of the cutting edge on the machining results. CIRP Ann 60:65-68. https://doi.org/10.1016/j.cirp.2011.03.078

14. Wang D, Jiao F, Mao X (2020) Mechanics of thrust force on chisel edge in carbon fiber reinforced polymer (CFRP) drilling based on bending failure theory. Int J Mech Sci 169:105336. https://doi.org/ 10.1016/j.ijmecsci.2019.105336

15. Geng D, Liu Y, Shao Z et al (2019) Delamination formation, evaluation and suppression during drilling of composite laminates: a review. Compos Struct 216:168-186. https://doi.org/10.1016/j. compstruct.2019.02.099

16. Geier N, Szalay T (2017) Optimisation of process parameters for the orbital and conventional drilling of uni-directional carbon fibre-reinforced polymers (UD-CFRP). Measurement 110:319334. https://doi.org/10.1016/j.measurement.2017.07.007

17. Pereszlai C, Geier N, Poór DI et al (2021) Drilling fibre reinforced polymer composites (CFRP and GFRP): an analysis of the cutting force of the tilted helical milling process. Compos Struct 262:113646. https://doi.org/10.1016/j.compstruct.2021.113646

18. Pereszlai C, Geier N (2020) A comparative analysis of wobble milling, helical milling and conventional drilling of CFRP. Int J Adv Manuf Technol 106:3913-3930. https://doi.org/10.1007/ s00170-019-04842-4

19. István Poór D, Geier N, Pereszlai C, Xu J (2021) A critical review of the drilling of CFRP composites: burr formation, characterisation and challenges. Compos Part B Eng 223:109155. https://doi. org/10.1016/j.compositesb.2021.109155

20. John KM, Thirumalai Kumaran S (2020) Backup support technique towards damage-free drilling of composite materials: A review. Int J Lightweight Mater Manuf 3:357-364. https://doi. org/10.1016/j.ijlmm.2020.06.001

21. Ameur MF, Habak M, Kenane M et al (2017) Machinability analysis of dry drilling of carbon/epoxy composites: cases of exit delamination and cylindricity error. Int J Adv Manuf Technol 88:2557-2571. https://doi.org/10.1007/s00170-016-8967-8

22. Davim JP, Reis P (2003) Drilling carbon fiber reinforced plastics manufactured by autoclave-experimental and statistical study. Mater Des 24:315-324. https://doi.org/10.1016/S0261-3069(03) 00062-1

23. Grilo TJ, Paulo RMF, Silva CRM, Davim JP (2013) Experimental delamination analyses of CFRPs using different drill geometries. Compos Part B Eng 45:1344-1350. https://doi.org/10.1016/j. compositesb.2012.07.057

24. Karpat Y, Değer B, Bahtiyar O (2014) Experimental evaluation of polycrystalline diamond tool geometries while drilling carbon fiber-reinforced plastics. Int J Adv Manuf Technol 71:1295-1307. https://doi.org/10.1007/s00170-013-5592-7

25. Seeholzer L, Scheuner D, Wegener K (2020) Analytical force model for drilling out unidirectional carbon fibre reinforced polymers (CFRP). J Mater Process Technol 278:116489. https:// doi.org/10.1016/j.jmatprotec.2019.116489

26. Lee J, Hong T, Seo C-H et al (2021) Implicit force and position control to improve drilling quality in CFRP flexible robotic machining. J Manuf Process 68:1123-1133. https://doi.org/10. 1016/j.jmapro.2021.06.038

27. Xu J, An Q, Chen M (2014) A comparative evaluation of polycrystalline diamond drills in drilling high-strength T800S/250F CFRP. Compos Struct 117:71-82. https://doi.org/10.1016/j. compstruct.2014.06.034

28. Xu J, El Mansori M (2017) Wear characteristics of polycrystalline diamond tools in orthogonal cutting of CFRP/Ti stacks. Wear 376-377:91-106. https://doi.org/10.1016/j.wear.2016.11.038

29. Jáuregui JC, Reséndiz JR, Thenozhi S et al (2018) Frequency and time-frequency analysis of cutting force and vibration signals for tool condition monitoring. IEEE Access 6:6400-6410. https://doi. org/10.1109/ACCESS.2018.2797003

30. Balázs BZ, Takács M (2020) Experimental investigation of surface characteristics and dynamic effects at micro milling of hardened hot-work tool steel. Int J Mach Mach Mater 22:504. https:// doi.org/10.1504/IJMMM.2020.111355

31. Su F, Zheng L, Sun F et al (2018) Novel drill bit based on the step-control scheme for reducing the CFRP delamination. J Mater Process Technol 262:157-167. https://doi.org/10.1016/j. jmatprotec.2018.06.037

32. Geier N, Szalay T, Takács M (2018) Analysis of thrust force and characteristics of uncut fibres at non-conventional oriented drilling of unidirectional carbon fibre-reinforced plastic (UD-CFRP) composite laminates. Int J Adv Manuf Technol 100:3139-3154. https://doi.org/10.1007/s00170-018-2895-8

33. Biró I, Szalay T (2017) Extension of empirical specific cutting force model for the process of fine chip-removing milling. Int J Adv Manuf Technol 88:2735-2743. https://doi.org/10.1007/ s00170-016-8957-x

34. Geier N (2020) Influence of fibre orientation on cutting force in up and down milling of UD-CFRP composites. Int J Adv Manuf Technol 111:881-893. https://doi.org/10.1007/ s00170-020-06163-3

35. Hadigheh SA, Wei Y, Kashi S (2021) Optimisation of CFRP composite recycling process based on energy consumption, kinetic behaviour and thermal degradation mechanism of recycled carbon fibre. J Clean Prod 292:125994. https://doi.org/10.1016/j.jclepro. 2021.125994

36. Turki Y, Habak M, Velasco R, Vantomme P (2017) Highlighting cutting mechanisms encountered in carbon/epoxy composite drilling using orthogonal cutting. Int J Adv Manuf Technol 92:685-697. https://doi.org/10.1007/s00170-017-0153-0

37. Abhishek K, Datta S, Mahapatra SS (2015) Optimization of thrust, torque, entry, and exist delamination factor during drilling of CFRP composites. Int J Adv Manuf Technol 76:401-416. https:// doi.org/10.1007/s00170-014-6199-3

Publisher's Note Springer Nature remains neutral with regard to jurisdictional claims in published maps and institutional affiliations. 